\title{
LA SEXUALIDAD PROCREADORA DE LAS MUJERES: REPRESENTACIONES MELANESIAS
}

\author{
Susana NAROTZKY \\ Universidad Autónoma de Madrid
}

\section{Introducción}

En esta intervención ${ }^{1}$ voy a intentar aportar un elemento comparativo a partir de unas sociedades muy distintas a las nuestras, muy alejadas geográficamente y a menudo marginadas de nuestra reflexión. Las incursiones antropológicas suelen ser un viaje de ida y vuelta. Nos aproximamos a otras sociedades con la ayuda de nuestros conceptos, elaborados en el debate científico de los diversos ámbitos del conocimiento; pero a la vuelta, la proximidad con formas distintas de comprender la existencia social nos invita a reflexionar sobre nuestras herramientas de análisis.

Lo que propongo es una reflexión sobre los conceptos de sexo y género, a través de una mirada sobre las imágenes de la sexualidad reproductiva de dos sociedades melanesias. El concepto de género en las ciencias sociales suele definirse como «un elemento constitutivo de las relaciones sociales basadas en las diferencias que distinguen los sexos..." (Scott, 1990: 44). El concepto de sexo, sin embargo, y su corolario la diferencia sexual, aparece como una categoría presocial, universal, como una categoría biológica, ergo "natural», ligada a la reproducción sexuada de la especie humana. El género aparece como una construcción social que crea y se crea en las relaciones sociales, que al tiempo produce e incorpora desigualdades sociales, que se transforma y que posee una clara especificidad histórica. El sexo aparece como el reducto "primario", biológico, de una diferencia significativa.

1 Este artículo fue presentado como ponencia en el Coloquio Internacional de la Asociación Española de Investigación de Historia de las Mujeres, Madrid, junio 1995. 
Algunas antropólogas feministas, desde hace algunos años, cuestionan este planteamiento y señalan el origen etnocéntrico de la diferenciación dicotómica sexual, ligado a nuestras ideas biológicas sobre la reproducción. Yanagisako y Collier (1987) dicen, por ejemplo: «Aunque no negamos que existan diferencias biológicas entre hombres y mujeres (tanto como existen entre hombres y entre mujeres), nuestra estrategia analítica se plantea si estas diferencias son la base universal de las categorías culturales «masculino" y "femenino". En otras palabras, discutimos en contra de la noción de que las variaciones inter-culturales en las categorías y desiguladades del género sean simplemente diversas elaboraciones y extensiones del mismo hecho natural" $(1987: 15 ; 48)$. En otras palabras, para estas antropólogas, el concepto dicotómico de la diferenciación sexual resulta problemático y por ende la posterior elaboración de un concepto de género que parta de ese irreductible principio de la reproducción sexual.

Pero veamos de dónde puede venir esa zozobra analítica que en un primer momento puede parecer desmesurada y hasta peregrina. Por ejemplo: ¡cómo se percibe la sexualidad reproductiva en otras sociedades?

Representaciones de la materia sexual: sustancias que se tranfieren

\section{El ejemplo hua (Papua Nueva Guinea) [Meigs, 1984]}

Para los hua de Papua Nueva Guinea que describe Meigs, El $n u$ es la «esencia vital" y se encuentra en las substancias sexuales, en otras substancias corporales (sangre, linfa, grasa corporal, sudor y en su forma gaseosa aliento) y en los productos vivos (alimentos: vegetales o animales) que contienen el $n u$ que se ha transferido con el trabajo productivo (1984: 40). Las mujeres tienen más nu, lo que aporta un estado blando, jugoso, de crecimiento rápido, fértil, frío; los hombres tienen menos $n u$ lo que se refleja en un estado seco, duro, de crecimiento lento, infértil, caliente (: 73-88). Para que sea posible la concepción tienen que concurrir dos circunstancias a) que por intervención de la luna y del marido durante el coito se abra el canal del nacimiento y b) una cantidad suficiente de semen y de sangre menstrual se mezclen en el útero. [La apertura del canal es fundamental porque es lo que caracteriza exclusivamente a las mujeres y les permite dar a luz mientras que los hombres que se quedan embarazados son incapaces de dar a luz (: 52-53)]. De un coágulo sólido de $n u$ de sangre menstrual se desarrolla un feto blando y húmedo, propiamente $n u$. Esta libera- 
ción del $n u$ húmedo es posible por una especie de explosión que crea pasajes y orificios [la vitalidad está relacionada al número y tamaño de los orificios corporales y por ello es superior en las mujeres] (: 116-119). Toda la sangre del feto y luego del adulto proviene de la mujer, es en origen sangre menstrual. El feto está compuesto de mucha sangre y un poco de semen (: 61$)$. El recién nacido es $n u$ en estado puro y para sobrevivir tiene que perder $n u$, hacerse más duro y seco. El crecimiento se concibe como un gasto de $n u$ (: 119). El comienzo de la menstruación en las mujeres señala la aparición de una nueva fuente de $n u$ (: 120) aunque las mujeres consideran la menstruación como una pérdida de $n u$ (: 41). Los jóvenes varones tienen que perder $n u$ en forma de sangre durante la iniciación para convertirse en hombres (: 71). Para los hombres, las relaciones sexuales son una transferencia de $n u$ (semen) a la mujer, mientras que las mujeres creen que provocan una menstruación más abundante (probablemente por la apertura del canal) y por tanto pérdida de $n u(: 41)$. El $n u$ existe en cantidades limitadas en una comunidad, y las personas lo adquieren a través de las transferencias (: 121).

El $n u$ se transfiere entre las personas y transforma su "composición sexual»: "Todas estas substancias [asociadas con la sexualidad: sangre menstrual, secreciones vaginales, fluidos del parto, semen] son transferibles entre las dos clases genitales, esta clasificación permite cruces: una persona genitalmente masculina puede ser clasificada como femenina por su contaminación por substancias femeninas, y una persona genitalmente femenina puede ser clasificada como masculina por haber transferido su contaminación fuera de su cuerpo» (: 7071). Así, los niños varones no iniciados, por su proximidad a los fluidos femeninos y su gran cantidad de $n u$ son en gran medida femeninos, lo mismo ocurre con los varones ancianos a quienes sus mujeres han transmitido durante toda su vida fluidos femeninos, son como mujeres. Por el contrario, las mujeres post menopáusicas que han tenido más de tres hijos/as han transferido tantos fluidos que se las considera como hombres hasta el punto que se las inicia formalmente y residen en la casa de los hombres (: 65-68). Además, a lo largo de su vida, tanto los hombres como las mujeres intentan manipular su contenido de $n u$ a través de actos como las sangrías rituales de los varones (con su significado contradictorio a la vez de pérdida y de regeneración de $n u$ ), o como la ingestión de alimentos húmedos o secos, blandos o duros, con más o menos nu.

Los hombres y las mujeres "representan los dos extremos de un continuum cuya identidad se reconoce explícitamente" (: 87). Difieren por su cantidad de 
$n u$ los hombres con su relativa deficiencia, las mujeres con su relativa abundancia. El desequilibrio de $n u$ en ambos casos, trae consigo ventajas e inconvenientes (falta de vitalidad en los hombres, falta de acción en las mujeres) que tanto unos como otros intentan equilibrar transformando la proporción de $n u$ que incorporan. Existe una ambivalencia fundamental en torno a las representaciones de la identidad sexual. Implícita, subyace una teoría del sexo como transferible y por tanto también, como dice Meigs: «El género de una persona no se encuentra encerrado en sus genitales pero puede fluir y cambiar con el contacto al entrar y salir las substancias de su cuerpo. El género no es un estado inmutable sino un flujo dinámico. Esta visión permite a la mayoría de las personas experimentar ambos géneros antes de su muerte" (1984: 72). Las substancias relacionadas con la sexualidad reproductiva "son transferibles entre las categorías genitales de sexo" y esto permite a las personas circular en un continuum sexual polarizado por la categorización genital pero representado por la incorporación de $n u$.

\section{El ejemplo sambia (Papua Nueva Guinea) [Herdt, 1984b, 1990]}

Los sambia reconocen y categorizan a los recién nacidos según sus caracteres sexuales primarios, es decir la genitalidad externa. Reconocen tres sexos, masculino, femenino y hermafrodita (Herdt 1990). Los caracteres sexuales secundarios que aparecen en la pubertad no se consideran, sin embargo, como un desarrollo automático de esa primera adscripción sexual. Se considera que la mujer se desarrolla más rápido y de forma natural, sin necesidad de ayuda externa, porque posee desde la época fetal un órgano menstrual activo, preparado y lleno de substancia (sangre) que le facilita alcanzar de forma natural la menarquia. Sin embargo también va a necesitar ayuda externa para desarrollar algunas caracterísiticas sexuales y adquirir algunas substancias necesarias a la procreación: los pechos y la leche, y en algunos casos para acelerar la menarquia. Existe una angustia muy generalizada respecto al desarrollo masculino en las sociedades de PNG. Entre los sambia se considera que el feto primero y luego el niño tienen unos órganos del semen inertes que son incapaces de producir internamente la substancia seminal. Por tanto, todo el desarrollo y maduración del varón - crecimiento, fuerza, pilosidad, y sobre todo la adquisición de semen - no pueden alcanzarse de forma natural y van a depender de la ayuda externa.

Los sambia creen que todo crecimiento biolbgico proviene de la ingestión o recepción de semen (o en menor grado de algunas substancias metafóricamente próximas -algunos alimentos- y de algunas actividades rituales). 1) El crecimiento 
inicial del feto es producto de una acumulación de semen por vía sexual genital; 2) la leche materna proviene de la ingestión por vía oral y posterior transformación del semen del esposo y por tanto el crecimiento del recién nacido en su época de lactante se debe al semen del padre; c) la ingestión de nueces de pandano, un alimento que se asocia con el semen, ayuda a crecer a los niños; d) la ingestión de semen por vía oral es la actividad principal de los rituales de iniciación masculinos y e) la fellatio heterosexual, con ingestión de semen, en los primeros tiempos del matrimonio, estimula la maduración definitiva de la mujer y la prepara a la procreación, además de constituir la materia prima para la producción de leche. En la sociedad sambia, por tanto, existen tres formas de actividad sexual: varón-varón oral (esta se subdivide en dos según el individuo sea receptor o donador de semen), varón-mujer oral y varón-mujer genital. Y además cada tipo de sexualidad está claramente ligada a una etapa del proceso de desarrollo de la sexualidad reproductiva de los individuos varones: 1) a partir de aproximadamente los siete años en que es inicidado en el primer grado hasta que alcanza la pubertad el varón entra en una relación homosexual como receptor; 2) desde la pubertad y hasta que contrae matrimonio el varón entra en una relación homosexual como donador; 3) hay una época corta de transición bisexual en la que todavía tiene algún contacto homosexual pero está iniciando las relaciones con su esposa, aunque probablemente con un énfasis en la fellatio heterosexual y 4) por último una etapa que dura hasta el final de la vida de exclusiva heterosexualidad genital. [Godelier, 1986: 74-75, señala para los baruya, vecinos de los sambia, la probable existencia de una homosexualidad femenina con transferencia de substancia (leche) durante los ritos de pubertad femeninos, pero no he encontrado otros casos en la etnografia del área consultada].

Todos estos contactos sexuales, los de uno y los de otro tipo, contribuyen directamente a la capacidad procreativa del receptor de semen: por vía oral, el niño se hace hombre con capacidad procreadora lo mismo que la mujer; o a la reproducción: por vía genital el hombre concibe en la mujer. Por lo tanto, la homosexualidad ritual masculina en estas sociedades es necesaria para crear individuos de sexo masculino (es decir, individuos con capacidad biológica de procrear) ${ }^{2}$, así como otras prácticas sexuales (por ejemplo, la fellatio heterose-

2 En este sentido es interesante recordar que en los casos de pseudo-hermafroditismo masculino, la iniciación es incompleta (hasta el primer o segundo estadio) o inexistente, y estos individuos no contraen matrimonio. De hecho, Herdt (1990) habla de un régimen de socialización de tres géneros. 
xual) son necesarias para crear caracterísiticas y substancias sexuales femeninas para asegurar una procreación viable thay que tener en cuenta como señala Gray la importancia de la leche materna para la supervivencia de las criaturas (1982)]. Para ambos sexos, la madurez sexual no se considera alcanzada hasta el nacimiento del segundo hijo/a.

Parece existir una ideología de la existencia limitada del semen en la sociedad sambia y por tanto esa substancia tiene que transferirse entre individuos y transformarse en otras substancias. Sin embargo, parece también que la ideología patrilineal del los sambia extiende a la reproducción social la creencia de la adquisición material de semen, puesto que la ingestión de la savia de ciertos árboles que crecen en el territorio del clan también regenera el semen de los miembros del clan. Existe por tanto una relación dialéctica entre la reproducción social de los patrilinajes y de sus derechos sobre unos territorios y la reproducción sexual de los miembros de esos patrilinajes, que se realiza mediante la circulación material y metafórica de semen.

El ejemplo de la homosexualidad ritual en Papua Nueva Guinea e Irian Jaya (Herdt 1984; 1984a; Godelier 1986; Lindenbaum 1987) es probablemente uno de los casos más reveladores que hacen de la sexualidad no sólo una realidad genital y genética sino también un constructo social. Si la sexualidad (biológica) [por contraste con el género] tiene como objeto definitorio la capacidad reproductora (biológica) debemos preguntarnos hasta qué punto, en todas las sociedades, existe una identidad «sexual-biológica» clara, inmediata, genital y "natural", sobre la que se construye una identidad socio-cultural de "género". El ejemplo de la homosexualidad ritual en Melanesia (sambia, baruya, kimampapuas entre otros) parece indicar que el sexo (biológico) es también un constructo social y cultural. Este ejemplo muestra también cómo una práctica sexual en apariencia no procreadora ${ }^{3}$ es necesaria para la adquisición de caracterísiticas y substancias sexuales fundamentales para la procreación.

\section{La inestabilidad de la identidad sexual}

Lo que estos ejemplos etnográficos parecen mostrarnos es que las diferencias que distinguen los sexos si bien hacen referencia a la reproducción biológica, no vienen unívocamente asociados a los caracteres genitales. La maduración

2 Desde el punto de vista ético de nuestros conocimientos científicos genético-biológicos. 
sexual de los seres humanos no se considera "natural", inherente a un crecimiento endógeno, sino que la sociedad debe intervenir para lograr el pleno desarrollo de personas capaces de procrear. Por otro lado, las substancias que producen determinadas identidades sexuales son consideradas como transferibles a lo largo de la vida. Las identidades sexuales, por tanto, no aparecen nunca como una adscripción inmediata y definitiva a una categoría genital. Son identidades fluidas, inestables, que los propios individuos y/o la sociedad en su conjunto, pueden y deben constantemente manipular. También la necesidad de acceder a una identidad sexual reproductiva obliga a las y los jóvenes a someterse a diversas instituciones - como los ritos de iniciación sambia - y a un entramado de costumbres que por supuesto producen determinadas relaciones de poder que estructuran la sociedad en su conjunto. El sexo aquí no es una categoría biológico-natural, claramente delimitada, dicotómica y definitiva. El sexo aparece más bien como un proceso social referente a la capacidad procreadora de las personas.

Pero entonces, jestamos hablando de sexo o de género? Una mujer hua, por ejemplo, ¿tiene una identidad sexual cambiante pero un sólo género? ¿ $\mathrm{O}$ la variación de su identidad sexual supone una variación de género (como parece suponer Meigs)? O bien ¿lo que he llamado identidad de sexo es en realidad género? A lo largo de una misma vida jcómo debemos entender las representaciones múltiples de la identidad sexual?

Para una mujer hua su identidad sexual está relacionada con la cantidad de $n u$ que incorpora, pero a su vez la mayor o menor cantidad de $n u$ la convierte en más peligrosa (contaminante) o más vulnerable (pura) y esta representación de su identidad sexual permite o impide que se adscriba a la categoría de los iniciados y de esta forma adquiera conocimiento y poder. La cantidad de $n u$ es al tiempo producto del desarrollo "natural" de las personas (por ejemplo de la menstruación debida, sin embargo, a la apertura del canal por la luna), de la intervención de los propios interesados mediante prácticas diversas, y de la simple existencia cotidiana y material que supone el gasto de energía (nu) en el trabajo que produce alimentos y reconstituye así la energía de las personas (de ahí la transferencia de $n u$ entre generaciones por mediación del trabajo y de los alimentos).

En cualquier caso, estas representaciones múltiples de la identidad sexual parecen ligadas a un proceso único de relaciones cambiantes entre los géneros en el proceso de reproducción de la sociedad en su conjunto. El género, como 
el sexo, se construye en un proceso dialéctico contínuo con otras relaciones necesarias de la sociedad: relaciones económicas, relaciones de poder. Así, la identidad de género tiene que asumir (y el concepto generalmente lo admite) el cambio, la variación que acompaña la duración de unas vidas inmersas en un contexto histórico y social. El concepto de identidad sexual también debería admitir la variación.

La creación social de la sexualidad reproductiva

El concepto de sexo aparecía como el núcleo «duro", científico-biológico, de nuestro concepto de género, un constructo social. Ahora también "sexo" se torna un concepto menos claro, menos evidente, menos dado por la evidencia cromosomática o genital. Porque el sexo - los caracteres humanos para la reproducción sexual - no es, en muchas sociedades, una cuestión simple e inmediata. El dimorfismo sexual es tan sólo el inicio de una ruta larga. La sexualidad va a tener que ser representada por la sociedad para poder ser realizada, y esta representación va a tener consecuencias materiales. Pero en el camino la sexualidad se construye al tiempo que produce y reproduce relaciones de trabajo y de poder entre hombres y mujeres, entre niños, jóvenes, adultos y viejos, entre los vivos y los muertos, entre los clanes (Weiner, 1976; 1978; 1980). No podemos hablar de un «antes», primario, del sexo, de la procreación y de la diferenciación sexual para las sociedades humanas. Igual que Rubin (1974) insistía en la cara económica del matrimonio heterosexual, alejándolo así de una supuesta naturalidad, debemos insistir en la cara social del sexo. El sexo es género.

\section{Conclusión: sexo y género}

La capacidad de procrear ha sido a menudo considerada como la piedra angular "biológica» de la construcción del género. Esto ha supuesto a priori una consideración de la sexualidad reproductiva como "natural» para todas las sociedades que no poseían medios técnicos de limitación de la fertilidad. Ha supuesto, por tanto, una consideración dualista y genital del género, basada en la heterosexualidad renroductiva. Los conceptos de sexo y género han sido diferenciados precisarnente en base a su referencia biológica o cultural respectivamente. Sin embargo casi siempre se interpreta el género como una construcción cultural sobre la base del sexo, de la sexualidad genital reproductiva. El sexo apa- 
rece entonces como el substrato más material (biológico) y por ello irreductible a consideraciones sociales y culturales concretas. La sexualidad reproductiva, aparece como el átomo universal sobre el que se construyen las sociedades humanas en gran medida a través de la construcción del género (piénsese en la división sexual del trabajo).

La materialidad de la procreación es indudable y, sin embargo, en las sociedades humanas es evidente que no es en modo alguno "natural». Las relaciones sociales afectan directamente esa materialidad primaria: las probabilidades, la realización y los resultados de un proceso reproductivo completo. Vemos, por ejemplo, cómo la monogamia heterosexual aumenta las probabilidades de fecundabilidad; cómo un acceso desigual y deficitario a ciertos recursos alimentarios por parte de las mujeres o de ciertas mujeres de ciertas clases sociales, puede retrasar la edad de la menarquia, crear ciclos ovulatorios irregualres, adelantar la menopausia y por tanto reducir no sólo las posibilidades de fecundación, sino también la viabilidad neonatal.

También las creencias afectan directamente la materialidad de la procreación. Las ideologías sobre la concepción, el desarrollo embrionario, el estatus del feto, el embarazo, el parto, la lactancia, la sexualidad y la sexuación, no son tan sólo expresiones de determinadas relaciones sociales ligadas a la reproducción biológica. Sino que enmarcan la práctica de los procesos sociales y al tiempo se transforman con ellos.

Por último, si resulta evidente que la procreación es imposible sin individuos sexuados y sexualmente maduros, comprendemos la importancia que ideologías de la maduración sexual (como las de las sociedades sambia o hua) tienen a la hora de establecer relaciones de poder y de solidaridad de unos individuos respecto a otros. Estos ejemplos resultan interesantes porque muestran cómo la sexualidad procreativa en su materialidad misma (cuando no se asocia automáticamente al dimorfismo genital innato como en occidente), se situa en un entramado denso de relaciones sociales que la «producen».

Si el sexo, la sexuación y la sexualidad procreativa tienen un inexcusable componente biológico, no son, en las sociedades humanas, exclusivamente biológicos: son también sociales y culturales. Podíamos decir que en la medida en que podemos discernir variaciones en la procreación de la especie humana, estamos ante un fenómeno social. Como conceptos, pues, sexo y género, ambos, son constructos culturales y sociales. El sexo, sin embargo, tiene un núcleo biológico irrecusable que es la sexualidad reproductiva de la especie, representada 
y realizada en las sociedades humanas. El género es un concepto ligado a la reproducción social en su totalidad y por tanto, la reproducción biológica -el sexo- puede y suele ser uno de sus componentes. Para el género, la sexualidad es un referente lejano que puede ser simplemente metáfora de complementaridad y continuidad social, pero también de cambio y transformación a lo largo de la vida, incluso de peligro (contaminación) y de crisis. Sexo y género se construyen ambos en el proceso social, que es al tiempo material e ideológico, forman parte de los campos de fuerza que estructuran las relaciones sociales y producen sistemas de desigualdades, pero al tiempo son producidos por estos. Como conceptos abarcan todo el ámbito de la sociedad y entran en relación dialéctica con los otros elementos fundamentales de la continuidad y el cambio social: la obtención de los recursos materiales para la vida y la capacidad de controlar otros seres humanos. Son el tercer elemento necesario, el que permite regular y organizar la reproducción biológica y la reproducción social: producir humanos y producir personas, para que una sociedad viva.

\section{Bibliografía}

Collier, J. F., y YanaGisako, S. J. (eds.) (1987): Gender and Kinship. Essays Toward a Unified Analysis, Stanford, California, Stanford University Press

GodelieR, M. (1986): La producción de Grandes Hombres. Poder y Dominación Masculina entre los Baruya de Nueva Guinea, Madrid, Akal.

Gray, B. (1982): «Enga Birth, Maturation and Survival: Physiological Characteristics of the Life Cycle in the New Guinea Highlands", en MacCormack, C. P. (ed.) (1982).

HeRDT, G. H. (1984a): «Ritualized Homosexual Behavior in the Male Cults of Melanesia, 1862-1983: An Introduction", en HerDT, G. H. (ed.) (1984).

- (1984b): «Semen Transactions in Sambia Culture», en Herdt, G. H. (ed.) (1984).

- (1990): «Mistaken Gender: 5-Alpha Reductase Hermaphroditism and Biological Reductionism in Sexual Identity Reconsidered", en American Antropologist, v. 92 \# 2.

HeRDT, G. H. (ed.) (1984): Ritualized Homosexuality in Melanesia, Berkeley, University of California Press.

Lindenbaum, S. (1987): «The Mystification of Female Labors", en Collier, J. F., y YANAGISAKO, S. (eds.) (1987).

MerGs, A. (1984): Food, Sex and Pollution. A New Guinea Religion, New Jersey, Rutgers University Press 
ReITER, R. (ed.) (1975): Toward an Anthropology of Women, Nueva York, Monthly Review Press.

Rubin, G. (1975): "The Traffic in Women: Notes on the 'Political Economy' of Sex», en ReITER, R. (ed.) (1975).

ScotT, J. W. (1990 [1986]): «El género una categoría útil para el análisis históricon, en Amelang, J., y NaSH, M. (eds.), Historia y género: Las mujeres en la Europa Moderna y Contemporánea, Alfons el Magnànim, IVEI, Valencia.

Weiner, A. B. (1976): Women of Value, Men of Renown. New Perspectives in Trobriand Exchange, Austin, University of Texas Press.

- (1978): "The Reproductive Model in Trobriand Society", en MankInd, v. 11 \# 3.

- (1980): "Reproduction: A Replacement For Reciprocity", en American Ethnologist, v. 7 \# 1.

Yanagisako, S. J., y Collier, J. F. (1987): "Toward a Unified Analysys of Gender and Kinship", en Collier, J. F., y Yanagisako, S. J. (eds.) (1987). 